\title{
Effect of Paracetamol (Acetaminophen) On Haematological and Reproductive Parameters in Male Albino Rats
}

\author{
Oyedeji K.O ${ }^{1}$., Bolarinwa A.F ${ }^{2}$, Ojeniran S.S. ${ }^{1}$ \\ ${ }^{l}$ Department of Physiology, Faculty of Basic Medical Sciences, Ladoke Akintola University of Technology, \\ P.M.B. 4000, Ogbomoso, Nigeria. \\ ${ }^{2}$ Department of physiology, College of Medicine, University of Ibadan, Ibadan, Nigeria.
}

\begin{abstract}
Paracetamol (acetaminophen) is a widely used over-the-counter analgesic and antipyretic drugs. Several studies have reported the toxic, gastrointestinal and musculoskeletal effect of this drug, but there is scanty information on its effect on blood chemistry and reproduction in albino rats. This study was designed to investigate the effect of this drug on haematological and reproductive parameters in male albino rats.

Paracetamol (7.5 mg/kg BW) was administered to the rats for 42 days (six weeks) for haematological and andrological study. Distilled water $(0.5 \mathrm{ml})$ served as control. Red Blood Cell (RBC) and Total White Blood Cell (TWBC) counts were determined using haemocytometer. PCV was determined by micro-haematocrit method. Semen analyses were done microscopically. Data were analysed using student's t-test at $p<0.05$.

Treatment of rats with paracetamol caused decrease in PCV and RBC counts relative to the controls. Treatment of rats with paracetamol also caused significant decrease in sperm motility and sperm count, but did not produce any pathological lesions on the testes.

These findings indicate that paracetamol caused deleterious effect on the blood chemistry and reproductive parameters in male albino rats.
\end{abstract}

Key words: Paracetamol, Albino rats, Red Blood Count, Total white blood count, Sperm motility.

\section{Introduction}

Paracetamol (Acelaminophen) is a non-prescription dug commonly used for antipyresis and analgesia (Anderson et al., 1998). It contains a phenol ring, as does oestradiol, and an acyl group as does progesterone (Creamer et al., 1998).

It has been reported that acute overdoses of paracetamol can cause potentially fatal liver damage and its toxicity is the foremost cause of acute liver failure in the Western world (Daly et al., 2008). It has been reported that high dose-usage (greater than $2000 \mathrm{mg}$ per day) of paracetumol does increase the risk of upper gastrointestinal complications such as stomach bleeding (Garcia and Hernanderz-Diaz, 2000). It is also effective in the treatment of musculoskeletal pain in dogs (Maddison et al., 2002). It has been reported to be lethal to snakes, and has been suggested as chemical control programme for the brown tree snake (Boiga irregularis) in Guam (Johnston et al., 2002).

However, due to dearth of information from literature on the effect of paracetamol on haematological and reproductive parameters in male albino rats, this study therefore aim at investigating the effect of paracetamol on these aforementioned parameters.

\section{Experimental Animals.}

\section{Materials And Methods}

Adult male albino rats weighing between $160 \mathrm{~g}$ and $180 \mathrm{~g}$ bred in the Animal House of Physiology Department, LAUTECH, Ogbomoso were used. They were housed under standard laboratory conditions with a 12 hours daylight cycle and had free access to feed and water; they were acclimatized to laboratory conditions for two weeks before the commencement of the experiments. All experiments were carried out in compliance with the recommendations of Helsinki's declaration on guiding principles on care and use of animals.

\section{Drug}

Paracetamol tablets (Emzoe Pharm Ltd) were bought from Jeopat pharmacy, Ogbomoso, Nigeria.

One thousand five hundred milligram $(1500 \mathrm{mg}$ ) of paracetamol were dissolved in $2000 \mathrm{ml}$ (2 litres) of distilled water to give a concentration of $0.75 \mathrm{mg} / \mathrm{ml}$.

The dosage of paracetamol administered in these studies were in accordance with those reported by Ucheya and Igweh (2006). 


\section{Experimental Design}

Ten animals were randomly divided into two groups with each group consisting of five rats. The two groups of rats were subjected to the following oral treatments once a day for 42 days:

Group I rats received $7.5 \mathrm{mg} / \mathrm{kg}$ BW of paracetamol

Group II rats received $0.5 \mathrm{ml}$ of distilled water as the control group.

Twenty-four hours (day 43) after the last dosing of the two groups, blood samples were collected and the animals were then euthenised by cervical dislocation for semen analysis. Histological preparation of the testes was also carried out.

\section{Body Weight}

Body weight of each rat was monitored on weekly basis.

\section{Collection of Blood Sample}

Blood samples were collected through the medial cantus into EDTA bottles for hormonal assay.

\section{Determination of Haematological Parameters}

The red blood cells (RBC) and white blood cells (WBC) counts were determined by the improved Neubauer haemocytometer method. The haemoglobin ( $\mathrm{Hb})$ concentration was determined according to Jain (1986), using the cyanomethaemoglobin method. The packed cell volume (PCV) was determined by the microhaematocrit method according to Dacie and Lewis (1991). Schilling method of differential lecukocyte count was used to determine the distribution of the various white blood cells (Mitruka and Rawnsley, 1977). Mean corpuscular volume $(\mathrm{MCV})$, mean corpuscular haemoglobin $(\mathrm{MCH})$ and mean corpuscular haemoglobin concentration (MCHC) were computed according to Jain (1986).

\section{Hormonal Assay}

Plasma samples were assayed for testosterone using the enzyme-linked immunosorbent assay (ELISA) technique using the Fortress kit.

\section{Semen Collection}

The testes were removed along with the epididymides. The caudal epididymides were separated from the testes, blotted with filter papers and lacerated to collect the semen.

\section{Semen Analysis}

Progressive sperm motility: This was done immediately after the semen collection. Semen was squeezed from the caudal epididymis onto a pre-warmed microscope slide $\left(27^{\circ} \mathrm{C}\right)$ and two drops of warm $2.9 \%$ sodium citrate was added, the slide was then covered with a warm cover slip and examined under the microscope using X400 magnification. Ten fields of the microscope were randomly selected and the sperm motility of 10 sperms was assessed on each field. Therefore, the motility of 100 sperms was assessed randomly. Sperms were labelled as motile, sluggish, or immotile. The percentage of motile sperms was defined as the number of motile sperms divided by the total number of counted sperms (i.e. 100) (Mohammad-Reza et al., 2005).

Sperm viability (Life/dead ratio): This was done by adding two drops of warm Eosin/Nigrosin stain to the semen on a pre-warmed slide, a uniform smear was then made and dried with air; the stained slide was immediately examined under the microscope using $\mathrm{x} 400$ magnification. The live sperm cells were unstained while the dead sperm cells absorbed the stain. The stained and unstained sperm were counted and the percentage was calculated (Laing, 1979).

Sperm morphology: This was done by adding two drops of warm Walls and Ewas stain (Eosin/Nigrosin stain can also be used) to the semen on a prewarmed slide, a uniform smear was then made and air-dried; the stained slide was immediately examined under the microscope using x400 magnification (Laing, 1979). Five fields of the microscope were randomly selected and the types and number of abnormal spermatozoa were evaluated from the total number of spermatozoa in the five fields; the number of abnormal spermatozoa were expressed as a percentage of the total number of spermatozoa.

Sperm count: This was done by removing the caudal epididymis from the right testes and blotted with filter paper. The caudal epididymis was immersed in $5 \mathrm{ml}$ formol-saline in a graduated test-tube and the volume of fluid displaced was taken as the volume of the epididymis. The caudal epididymis and the $5 \mathrm{ml}$ formol-salline were then poured into a mortar and homogenized into a suspension from which the sperm count was carried out using the improved Neubauer haemocytometer under the microscope. 


\section{Testicular Histology}

After weighing the testes, they were immediately fixed in Bouin's fluid for 12 hours and the Bouin's fixative was washed from the samples with $70 \%$ alcohol. The tissues were then cut in slabs of about $0.5 \mathrm{~cm}$ transversely and the tissues were dehydrated by passing through different grades of alcohol: $70 \%$ alcohol for 2 hours, 95\% alcohol for 2 hours, $100 \%$ alcohol for 2 hours, $100 \%$ alcohol for 2 hours and finally $100 \%$ alcohol for 2 hours. The tissues were then cleared to remove the alcohol, the clearing was done for 6 hours using xylene. The tissues were then infilterated in molten Paraffin wax for 2 hours in an oven at $57^{\circ} \mathrm{C}$, thereafter the tissues were embedded. Serial sections were cut using rotary microtone at 5 microns $(5 \mu \mathrm{m})$. The satisfactory ribbons were picked up from a water bath $\left(50^{\mathrm{O}}-55^{\circ} \mathrm{C}\right)$ with microscope slides that had been coated on one side with egg albumin as an adhesive and the slides were dried in an oven. Each section was deparaffinized in xylene for 1 minute before immersed in absolute alcohol for 1 minute and later in descending grades of alcohol for about 30 seconds each to hydrate it. The slides were then rinsed in water and immersed in alcoholic solution of hematoxylin for about 18 minutes. The slides were rinsed in water, then differentiated in $1 \%$ acid alcohol and then put inside a running tapwater to blue and then counterstained in alcoholic eosin for 30 seconds and rinsed in water for a few seconds, before being immersed in 70\%, 90\% and twice in absolute alcohol for 30 seconds each to dehydrate the preparations. The preparations were cleared of alcohol by dipping them in xylene for 1 minute. Each slide was then cleaned, blotted and mounted with DPX and cover slip, and examined under the microscope. Photomicrographs were taken at x40, x100 and x400 magnifications

\section{Statistical Analysis}

The mean and standard error of mean (S.E.M.) were calculated for all values. Comparisons between the control and the treated groups were done using the student's t-test. Differences were considered statistically significant at $\mathrm{p}<0.05$.

\section{Effect on Haematological Parameters}

\section{Results}

Treatment of rats for 42 days with $7.5 \mathrm{mg} / \mathrm{kg}$ BW of paracetamol caused significant $(\mathrm{p}<0.05)$ reductions in $\mathrm{PCV}, \mathrm{Hb}$ and $\mathrm{RBC}$ values relative to their controls, but caused no significant $(\mathrm{p}>0.05)$ changes in $\mathrm{MCV}, \mathrm{MCHC}, \mathrm{MCH}$, plateled, neutrophil, lymphocyte, eosinophil and monocyte values relative to their controls.

Table 1: Effect of 42 days treatment with Paracetamol on haematological parameters $(\mathrm{n}=5, * \mathrm{P}<0.05)$

\begin{tabular}{lll}
\hline Parameters & Control & Treated \\
\hline $\mathrm{PCV}(\%)$ & $37.40 \pm 1.29$ & $33.00 \pm 0.71^{*}$ \\
$\mathrm{Hb}(\mathrm{g} / \mathrm{dl})$ & $11.86 \pm 0.44$ & $10.62 \pm 0.32^{*}$ \\
$\mathrm{RBC}\left(\times 10^{6} / \mu \mathrm{l}\right)$ & $6.45 \pm 0.34$ & $5.55 \pm 0.10^{*}$ \\
$\mathrm{MCV}(\mathrm{FL})$ & $58.24 \pm 1.28$ & $59.84 \pm 0.85$ \\
$\mathrm{MCHC}(\mathrm{g} / \mathrm{dl})$ & $31.68 \pm 0.53$ & $32.36 \pm 0.49$ \\
$\mathrm{MCH}(\mathrm{pg})$ & $18.50 \pm 0.61$ & $19.22 \pm 0.43$ \\
$\mathrm{TWBC}\left(\times 10^{3} / \mu \mathrm{l}\right)$ & $7.88 \pm 0.59$ & $9.67 \pm 0.72$ \\
Platelets $\left(\times 10^{5} / \mu \mathrm{l}\right)$ & $1.28 \pm 0.08$ & $1.43 \pm 0.12$ \\
Neutrophils $(\%)$ & $35.80 \pm 3.54$ & $45.20 \pm 5.44$ \\
Lymphocytes $(\%)$ & $62.00 \pm 3.45$ & $50.80 \pm 5.67$ \\
Eosinophils $(\%)$ & $1.40 \pm 0.51$ & $1.80 \pm 0.86$ \\
Monocytes $(\%)$ & $0.80 \pm 0.20$ & $0.60 \pm 0.40$ \\
\hline
\end{tabular}

\section{Effect on Body Weight}

Treatment of rats for 42 days with $7.5 \mathrm{mg} / \mathrm{kg}$ BW of paracetamol caused non-significant $(\mathrm{p}>0.05)$ changes in body weight relative to the control. 


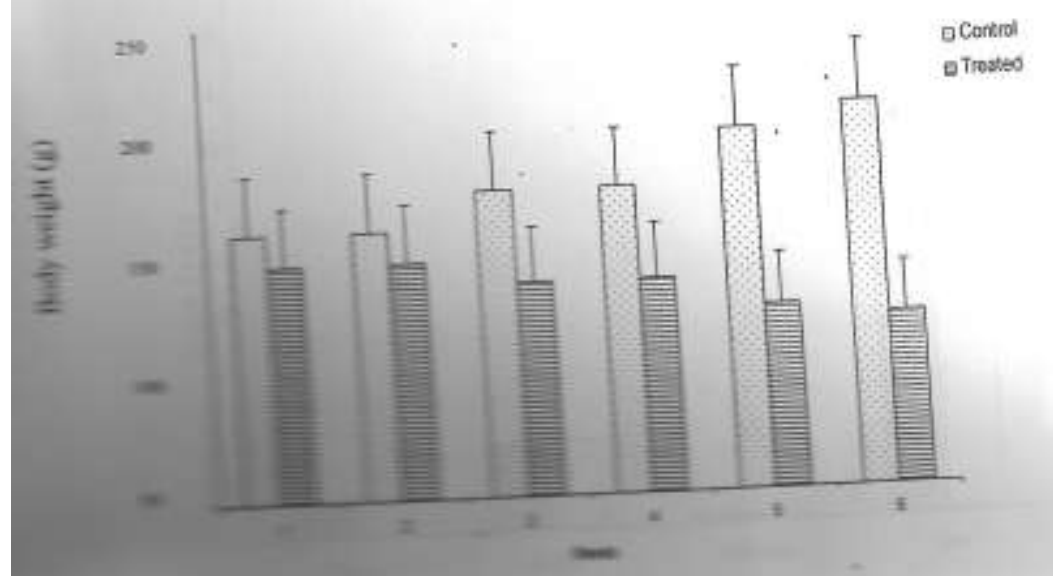

Figure 1: Effect of 42 days treatment with Paracetamol $(7.5 \mathrm{mg} / \mathrm{kg} \mathrm{BW})$ on the body weights of male rats $(\mathrm{n}=5$, $* \mathrm{p}<0.05)$

\section{Effect on Sperm Characteristics}

Treatment of rats for 42 days with paracetamol $(7.5 \mathrm{mg} / \mathrm{kg} \mathrm{BW})$ caused significant $(\mathrm{P}<0.05)$ decrease in sperm motility relative to the control. Paracetamol $(7.5 \mathrm{mg} / \mathrm{kg} \mathrm{BW}$ ) caused non-significant ( $>0.05)$ change in sperm viability (life/dead) but caused significant $(\mathrm{p}<0.05)$ increase in the percentage of abnormal sperm cells and significant $(\mathrm{p}<0.05)$ decrease in sperm count.

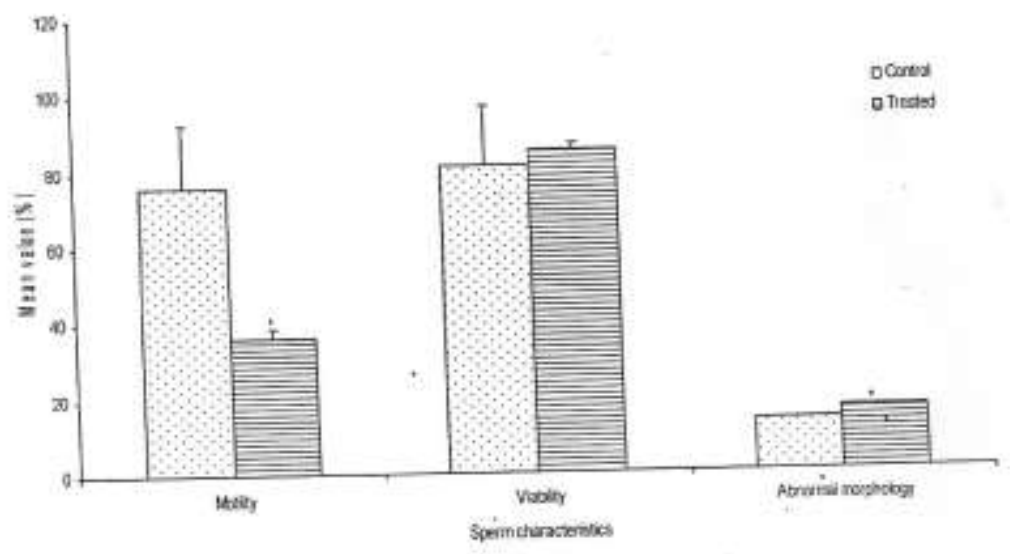

Figure 2:Spermogram showing the effect of 42 days treatment of rats with $7.5 \mathrm{mg} / \mathrm{kg}$ BW paracetamol on sperm characteristics $\left(\mathrm{n}=5,{ }^{*} \mathrm{p}<0.05\right)$

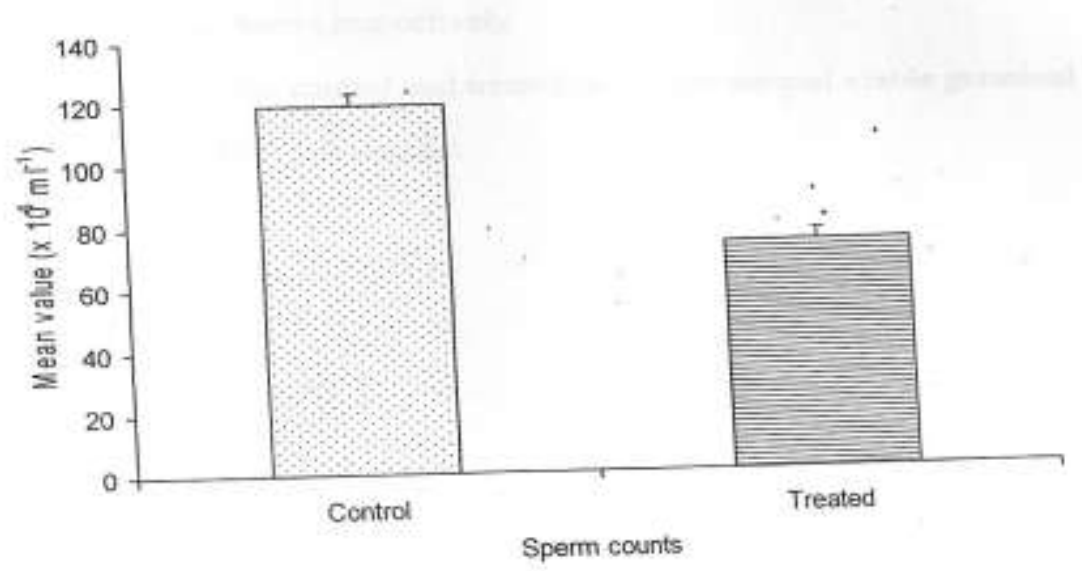

Figure 3: Spermogram showing the effect of 42 treatments of rats with $7.5 \mathrm{mg} / \mathrm{kg} \mathrm{BW}$ of paracetamol on sperm counts. $(n=5, * p<0.05)$ 


\section{Histopathological Findings}

Rats treated for 42 days with paracetamol $(7.5 \mathrm{mg} / \mathrm{kg} \mathrm{BW})$ presented with normal germinal epithelium with no visible lesion which is similar to what was observed in the control.

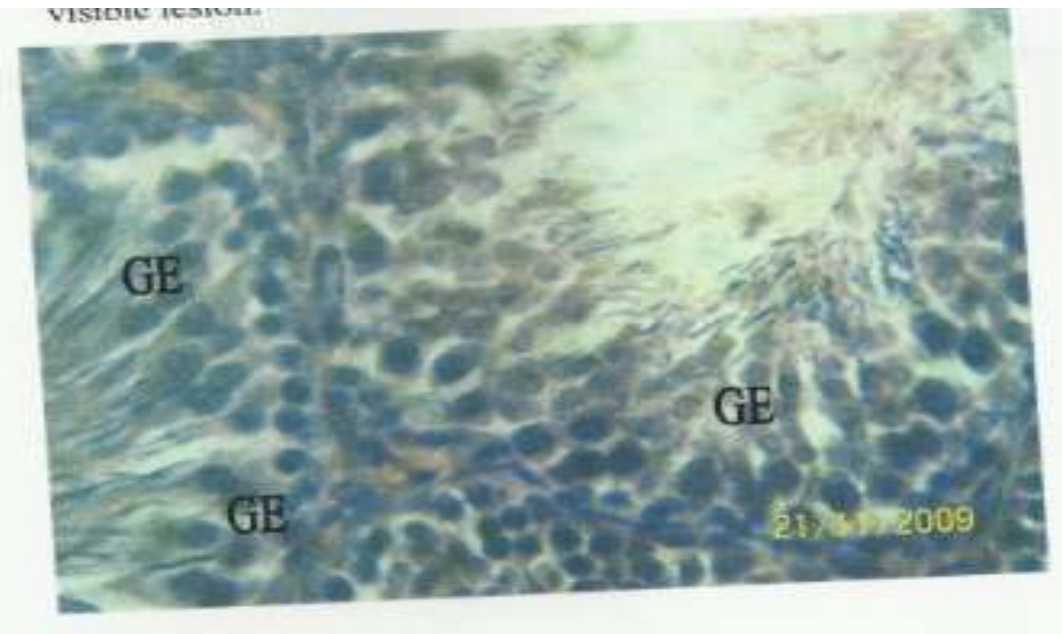

Plate 1: Effect of $0.5 \mathrm{ml}$ distilled water (control) on the testes at $\mathrm{x} 400$.

Photomicrograph showing normal germinal epithelium (GE) with no visible lesion.

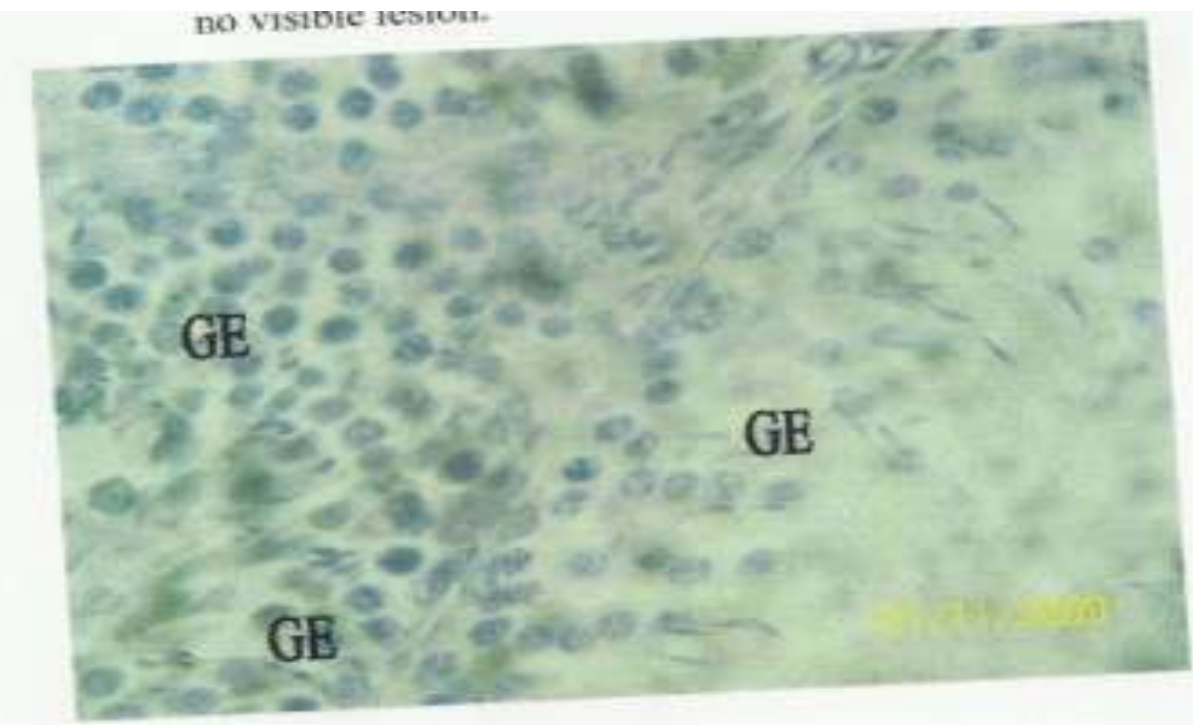

Plate 2: Effect of $7.5 \mathrm{mg} / \mathrm{kg} \mathrm{BW}$ paracetamol on the testes at $\mathrm{x} 400$.

Photomicrograph showing normal germinal epithelium (GE) with no visible lesion.

\section{Discussion}

The haematological study has shown that treatment of rats with paracetamol caused significant $(\mathrm{p}<0.05)$ decrease in RBC count which could indicate that there were destruction of matured RBC and reduction in the rate of erythropoiesis. This could also imply that paracetamol has the potential to inhibit erythropoietin release from the kidneys. Similar report was given by Daniel and Clement (2008) in rats treated with Dennettia tripetala extract. Paracetamol caused significant decrease in haemoglobin $(\mathrm{Hb})$ concentration which suggest a reduction in the oxygen-carrying capacity of blood and the amount of oxygen-carrying capacity of blood and the amount of oxygen delivered to the tissues. Similar report was given by Adedapo et al., (2007) in rats treated with A. cordifolia and S. Virosa extracts. Paracetamol also caused significant decrease in PCV value which could indicate the induction of anaemia. Similar report was given by Biu et al. (2009) in rats treated with aqueous Neem extract. Paracetamol caused non-significant changes in total WBC, neutrophil, eosinophil, monocyte and lymphocyte counts, which suggest that the immune system have not been compromised. It also caused non-significant change in platelet count which probably indicates its inability to stimulate haemostasis.

Paracetamol caused non-significant changes in body weight of rats after treatment of rats for 42 days, this suggests that paracetamol was not toxic to the animals as well as non-androgenic in nature, since androgens 
are known to possess anabolic activities. Similar report was given by Gonzales et al. (2006) in rats treated with Lepidium meyenii extracts.

The andrological results show that treatment of rats for 42 days with paracetamol caused significant decrease in sperm motility. Similar report was given by Verma et al. (2002) in rats treated with Sarcostemma acidum extract. This suggest that aspirin was able to permeate the blood-testis barrier with resultant alteration in the microenvironment of the seminiferous tubules, since it has been reported that the decrease in sperm motility caused by chemical agents was due to their ability to permeate the blood-testis barrier (Baldessarini, 1980) and thus, creating a different microenvironment in the inner part of the wal of the seminiferous tubules from that in the outer part (Bloom and Fawcett, 1975).

Paracetamol caused significant increase in the percentage of morphologically abnormal sperm cells as well as significant decrease in sperm motility in the treated rats. This could be due to the ability of paracetamol to either interfere with spermatogenic processes in the seminiferous tubules or epididymal functions which may result in alteration of spermatogenesis (William, 2000; Bowman and Rand, 1985). Similar report was given by Krishnamoorthy et al. (2007) in Terminalia chebula extract treated rats.

Rats treated with paracetamol presented with normal germinal epithelium with no visible lesion. Similar results were reported by Moundipa et al. (1999) in rats treated with Hibiscus macranthus and Basella alba extracts. This suggest that paracetamol has no toxic effect on the exocrine function of the testes.

Further study will be carried out to see the effect of this drug on reproductive hormonal levels in male albino rats.

\section{References}

[1] Adedapo AA, Abatan MO, Olorunsogo OO (2007): Effects of some plants of the spurge family on haematological and biochemical parameters in rats. VETERINARSKI ARHIV 77 (1), $29-38$

[2] Anderson BJ, Hollford NHG, Woolard GA (1998): Paracetamol plasma and cerebrospinal fluid pharmacokinetics in children. Br J Clin Pharmacol; $46: 237-43$

[3] Baldessarini RJ (1980): In drugs and the treatment of psychiatriod disorders. The pharmacological basis of therapeutics Ed. By Goodman and Gilman. Macmillan Pub. Co. Inc. pp. 301-417.

[4] Biu AA, Yusufu SD, Rabo JS (2009): Studies on the effects of aqueous leaf extracts of Neem Azadirachta indica on haematological parameters in chicken. African scientist Vol. 10 No 4 pp $189-192$.

[5] Bloom W, Fawcett DW (1975): Male reproductive system. In the textbook of Histology. Saunders Company, Philadelphia.

[6] Bowman WC, Rand MJ (1985): The reproductive system and drugs affecting the reproductive systems. Textbook of pharmacology, 2nd edition, 20:1-8.

[7] Cramer DW, Harlow BL, Titus-Ernstoff L, Bohike K, Welch WR, Greenberg ER (1998): Over- the-counter analgesics and risk of ovarian cancer. Lancet, 351: $104-7$.

[8] Dacie JV, Lewis SM (1991): Practical haematology, 7th edition ELBS with Churchill Livingston, England, pp 37-85

[9] Daly FF, Fountain JS, Murray L, Graudins A, Buckley NA (2008): "Guidelines for the management of paracetamol poisoning in Australia and New Zealand - explanation and elaboration. A consensus statement from clinical toxicologists consulting to the Australasian poisons information centres". Med. J. Aust. 188(5): 296 - 301.

[10] Daniel EI, Clement ON (2008): Effect of ethanolic extract of Dennettia tripetala fruit on haematological parameters in albino Wista rats. Nigeria Journal of Physiological Sciences 23(1-2):13-17.

[11] Garcia RLA, Hernandez - Diaz S (2000): "The risk of upper gastrointestinal complications associated with non-steroidal antiinflammatory drugs, glucocorticoids, acetaminophen, and combinations of these agents". Arthritis Research and Therapy 3:98.

[12] Gonzales C, Rubio J, Gasco M, Nieto J, Sandra Y, Gonzales GF (2006): Effect of short-term and long-term treatments with three ecotypes of Lepidium meyenii (MACA) on spermatogenesis in rats. Journal of Ethnnopharmacol. (103), 448 - 454.

[13] Jain NC (1986): Schalm's Veterinary Haematology 4th ed. Lea and Fabiger, Philadelphia.

[14] Johnston J, Savarie P, Primus T, Eisemann J, Hurley J, Kohler D (2002): "Risk assessment of an acetaminophen baiting program for chemical control of brown tree snakes in Guam: evaluation of baits, snake residues, and potential primary and secondary hazards". Enviro Sci Technol (17): 3827 - 33

[15] Krishnamoorthy P, Viathinathan S, Rani V, Bhuvaneswari A (2007): Effect of Terminalia chebula fruit extract on lipid peroxidation and antioxidative system of testis of albino rats. African Jouranl of Biotechnology, Vol. 6 (16), Pp 1888 - 1891.

[16] Laing JA (1979): Fertility and infertility in domestic animals. 3rd edition 1979 Bailliere Tindall, a division of Cassell Lt.

[17] Maddison JE, Stephen WP, David C (2002): Small Animal Clinical Pharmacology. Elsevier Health sciences pp 260-261

[18] Mitruka BM, Rawnsley H (1977): Clinical, biochemical and haematological references values in normal experimental animals. Masson Publishing USA Inc. Pp. 53-54.

[19] Mohammad - Reza P, Farzaneh D, Taherch TK, Zoherb PP (2005): The effects of hydroalcholic extract of Actinidia chinensis on sperm count and motility, and blood levels of estradiol and testosterone in male rats. Achieves of Iranina Medicine, Volume 8 , Number 3, 211-216

[20] Moundipa FP, Kamtchouing, Koueta N, Tantchou J, Foyang NPR, Mbiapo FT (1999): Effects of aqueous extracts of Hibiscus macranthus and Basella alba in mature rat testis function. Journal of ethnopharmacology (65)) $133-139$.

[21] Ucheya RE, Igweh JC (2006): Histological changes in kidney structure following a long-term administration of paracetamol in pregnant Sprague Dawley rats. Nigeria Journal of Physiological Sciences 21(1-2): $77-81$

[22] Verma PK, Sharma A, Annu M, Prachi S, Gupta RS, Joshi SC, Dixit VP (2002): Effect of Sarcostemma acidum stem extract on spermatogenesis in male albino rats. J. Androl. 4(1): 43 - 47.

[23] William KW (2000): Hormones and Hormone antagonists. In: Remington, The Science and Practise of Pharmacy, vol 11, 20th edition 77: 1390-1391 